\title{
Numerical Modeling and Experimental Verification of Residual Stress in Autogenous Laser Welding of High-Strength Steel
}

\author{
Wei Liu • Junjie Ma • Fanrong Kong • Shuang Liu • \\ Radovan Kovacevic
}

Accepted: 15 January 2015 / Published online: 23 January 2015

(C) Springer New York 2015

\begin{abstract}
A three-dimensional finite element (FE) model was developed to numerically calculate the temperature field and residual-stress field in the autogenous laser welding process. The grid independence of the FE model was verified to eliminate the variation of the heat flux between adjacent elements. A cut-off temperature method with combination of the tensile testing was used to consider the effect of hightemperature material properties on the numerical simulation. The effect of the latent heat of fusion and evaporation was also taken into consideration. High compressive initial stress was presented in the selected high-strength steel plates. A subroutine was written to consider the initial stress in the FE mode. Predicted residual stress agreed well with experimental data obtained by an X-ray diffraction technique. Results showed that the transverse and longitudinal residual stresses prevailed in the autogenous laser welding process, and the thermal stress concentration occurred in the molten pool and its adjacent regions. The effect of the welding speed on the distribution of residual stress was also studied. The values of residual stress decreased with an increase in the welding speed.
\end{abstract}

Keywords Laser welding $\cdot$ Residual stress $\cdot$ Finite element model

\section{Introduction}

Laser beam welding is widely recognized as an important modern joining approach due to its advantages, such as a high power density, a high welding rate, and a high welding quality. Nowadays, laser welding is mainly used to join the thin metal sheets, such as welding of thin zinc-coated steel sheets at a high welding speed [1]. By combing a filler material [2] or an electric arc [3], thick steel plates could also be successfully welded.

W. Liu $\cdot$ J. Ma $\cdot$ F. Kong $\cdot$ S. Liu $\cdot$ R. Kovacevic $(\bowtie)$

Research Center for Advanced Manufacturing, Southern Methodist University, 3101 Dyer Street, Dallas, TX, USA

e-mail: kovacevi@lyle.smu.edu 
Laser beam welding produces a narrower heat affected zone (HAZ) and a higher cooling rate, resulting in the fact that the distribution of the residual stress induced by laser welding is different from the distribution of the traditional arc welding techniques [4]. Residual stress has a detrimental effect on the service performance of the welded structures, especially the tensile residual stress that prompts the initiation and propagation of the fatigue crack $[5,6]$.

Numerical methods are usually used to investigate the three-dimensional (3D) residual-stress field as well as the evolution of the residual stress during welding [7]. The effectiveness of using numerical simulation methods to analyze the residual stress has been demonstrated in a number of publications. Deng et al. [8] successfully predicted the residual stresses produced in the tungsten inert gas arc welding process by using the finite element (FE) method. The results showed that the phase transformation has an important influence on the welding residual stress for the medium carbon steel. Zain-ul-Abdein et al. [9] developed an FE model to analyze the laser-weldinginduced residual stresses. The results showed that the longitudinal residual stress has a dominant influence on the distortion and failure of the welded structures with respect to the transverse and through-thickness residual stresses. Kong and Kovacevic [10] studied residual stresses induced in the hybrid laser-arc welding process. The "death and birth" technique was used to simulate the added filler wire in the groove, and a hybrid heat source model was applied to consider the combination of the arc energy and the laser beam power.

There are three major challenges to fulfill a successful thermo-mechanical numerical simulation. First, the variation of the heat flux between adjacent elements, which is related to the grid independence and time step [11], should be eliminated. Radaj [12] recommended that the temperature difference between adjacent time steps should not exceed $50{ }^{\circ} \mathrm{C}$. The variation of the heat flux can be mitigated by using finer meshes that will, however, increase the computing time [13]. A compromise between decreasing the heat flux's variation and reducing the computing time needs to be provided. Second, the effect of high-temperature material properties on the numerical results should also be taken into consideration. Material properties change with an increase in the temperature, and this change is non-linear. Blodgett [14] pointed out that when the temperature of the material increases, the yield stress of the material decreases, the elastic modulus decreases, but the thermal expansion coefficient increases. Zhu and Chao [15] studied the effect of temperature-dependent material properties on the numerical calculation. They found that in comparison to other material properties, the yield stress is the most important factor for the thermo-mechanical numerical analysis of the welding process. Third, the thermal history, especially during the cooling process, significantly affects the formation of residual stress. Tsai and Kim [16] concluded that the cooling cycle rather that the heating cycle has a decisive influence on the formation of residual stresses. Radaj [12] pointed out that the cooling process below half the melting temperature determines the formation of residual stresses. In this temperature range, the yield stress and elastic modulus increase sharply, and the viscoplastic process diminishes. Thus, the accuracy of thermal results in the FE analysis needs to be guaranteed.

In this study, the residual stress induced by autogenous laser welding was experimentally and numerically investigated. An FE model was developed to study the evolution and distribution of the 3D residual-stress field. An X-ray diffraction (XRD) 
technique, which was commonly used to assess the residual stress due to the nondestructive and surface-sensitive characteristics [17], was selected to measure the residual stress at the top surface of the welded plates. Numerical results were verified by the experimental data. The effects of the grid independence, high-temperature material properties, and initial stress on the numerically-predicted residual stress were considered. The effect of the heat input during welding on the residual stress was also investigated by varying the welding speed.

\section{Experimental Setup}

High-strength and low-alloy ASTM A514 steel plates in a square butt-joint configuration with the dimensions of $80 \mathrm{~mm}$ (length) $\times 40 \mathrm{~mm}$ (width) $\times 6.7 \mathrm{~mm}$ (thickness) were welded. The edges of the steel plates were ground and cleaned to ensure the cleanliness and edge dimension. Figure 1 shows the experimental setup. A continuous wave (CW) YLS-4000 IPG fiber laser with a maximum power of $4 \mathrm{~kW}$ was used. A collimating lens of $150 \mathrm{~mm}$ and a focusing lens of $200 \mathrm{~mm}$ were selected to achieve a $0.6 \mathrm{~mm}$ laser focusing spot. The laser head was tilted $5^{0}$ with respect to the vertical axis. A 6-axis robotic arm was used to control the needed motion during welding. Argon was supplied to the laser head as the shielding gas with a flow rate of $1 \mathrm{~m}^{3} / \mathrm{h}$. Thermocouples (TC) were installed to measure the temperature history at specific locations near the weld center.

An XRD technique was used to measure the residual stress at the top surface of the welded plates. Parameters for the XRD measurement are shown in Table 1 [18]. The distance between adjacent measuring points was $1 \mathrm{~mm}$. An electrochemical polishing method was used to achieve a smooth weld-bead surface. After the measurement was completed, the welded plates were cut by an abrasive water-jet cutting machine. The samples were then mounted, ground, polished, and etched by using standard metallographic procedures. An optical microscope was used to view the cross-sections of the samples. Tensile testing was performed on the A514 steel plates to obtain its mechanical properties at room temperature. The loading rate was set at $1 \mathrm{~mm} / \mathrm{min}$.

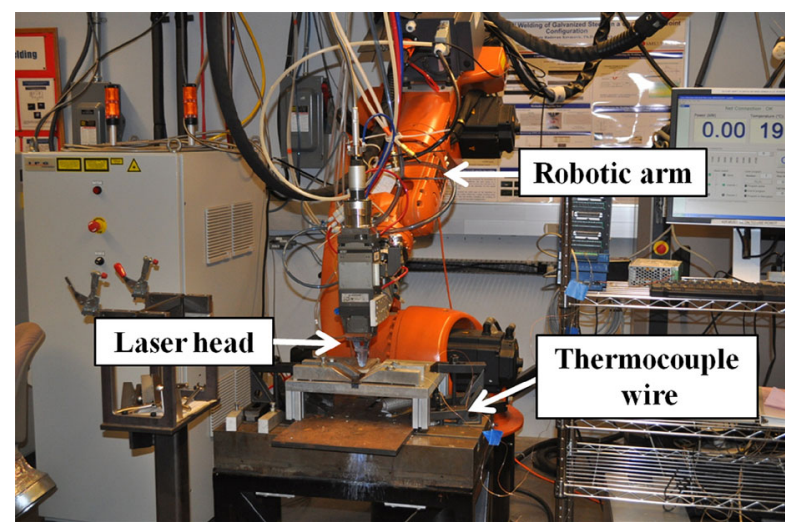

Fig. 1 Experimental setup for the autogenous laser welding 
Table 1 Operating parameters for the XRD measurement

\begin{tabular}{|c|c|c|c|c|c|c|c|}
\hline Material & Symmetry & $\begin{array}{l}\text { Diffraction } \\
\text { plan }\end{array}$ & $\begin{array}{l}\text { Brag } \\
\text { angle }\end{array}$ & $\begin{array}{l}\text { Radiation } \\
\text { type }\end{array}$ & $\begin{array}{l}\text { Collimator } \\
\text { diameter }\end{array}$ & $\begin{array}{l}\text { Maximum beta } \\
\text { angle interval }\end{array}$ & $\begin{array}{l}\text { Number of } \\
\text { beta angle }\end{array}$ \\
\hline Steel-Ferritic & $\mathrm{BBC}$ & $\left(\begin{array}{lll}2 & 1 & 1\end{array}\right)$ & $156.41^{0}$ & Cr_K-Alpha & $1.0 \mathrm{~mm}$ & $-20^{0}$ to $20^{0}$ & 5 \\
\hline
\end{tabular}

\section{Finite Element Model}

\section{Governing Equation}

The governing equation depicting the spatial and temporal temperature distribution $T(x$, $y, z, t)$ in the FE model can be specialized to the following differential equation by solving the Fourier's second law [19]:

$$
k \nabla^{2} T-\rho C_{p} v \nabla T+\dot{q}_{\text {LASER }}(x, y, z, t)=\rho C_{p} \frac{\partial T}{\partial t}
$$

where $k$ is thermal conductivity, $\rho$ is material density, $C_{p}$ is the specific heat of the material, $v$ is the velocity of the workpiece, and $t$ is time. The conservation of energy is expressed in Eq. 1. The convection term in this work was neglected to simplify the numerical solution. An artificially-increased thermal conductivity was applied when the temperature was above the melting point in order to compensate for the convective flow of the molten material in the weld pool [20].

Initial condition is specified is:

$$
T(x, y, z, 0)=T_{0}
$$

A lumped heat transfer coefficient is applied to combine heat losses from the model surfaces based on the Vinokurov's empirical relationship [21, 22].

$$
h=2.4 \times 10^{-3} \varepsilon T^{1.61}
$$

where $h$ is the lumped heat transfer coefficient, $\sigma$ is the Stefan-Boltzmann constant for radiation $\left(5.67 \times 10^{-8} \mathrm{Wm}^{-2} \mathrm{~K}^{-4}\right)$, and $\varepsilon$ is emissivity. The values of $\varepsilon$ are presented in Table 2 .

\section{Heat Source Model}

According to the metallographical images, a cone-shaped fusion zone (FZ) was achieved by using autogenous laser welding. The heat source model that describes a

Table 2 Values of $\varepsilon$ used in the FE model [22, 23]

\begin{tabular}{lllllllllllllll}
\hline Temperature, ${ }^{\circ} \mathrm{C}$ & 0 & 100 & 200 & 300 & 400 & 500 & 600 & 700 & 800 & 1000 & 1500 & 1590 & 1840 & 2860 \\
\hline$\varepsilon$ & 0.2 & 0.4 & 0.45 & 0.48 & 0.5 & 0.54 & 0.56 & 0.57 & 0.58 & 0.59 & 0.6 & 0.6 & 0.6 & 0.62 \\
\hline
\end{tabular}


conical Gaussian profile is given as the following [24]:

$$
q(r, z)=\frac{2 P}{\pi r_{0}^{2} Y} \exp \left(1-\frac{r^{2}}{r_{0}^{2}}\right)\left(1-\frac{y}{Y}\right)
$$

where $P$ is the laser beam power, $r_{0}$ is the average keyhole radius, $r$ is the current radius, $y$ is the current thickness, and $Y$ is the specimen thickness.

Latent Heat of Fusion and Evaporation

In this study, the thermal effect of solid-to-liquid phase transformation was considered by artificially increasing the specific heat, $C_{p}$, in the temperature range between the solidus and liquidus temperature ( $T_{S}$ and $T_{L}$, respectively). Solid-to-liquid phase transformation releases the latent heat of fusion, resulting in an increase in the enthalpy, $h$, $[25]$.

$$
h=\rho C_{p} T+\rho L_{f} f=\rho C_{p}{ }^{\prime} T
$$

where $L_{f}$ is the latent heat of fusion, $\rho$ is the density, and $f$ is the mass proportion of the molten material, and $C_{p}{ }^{\prime}$ is the artificially-increased specific heat. $\rho$ is set to be constant, and $f$ is given as the following [26]:

$$
f=\left\{\begin{array}{cc}
0 & T<T_{S} \\
\frac{T-T_{S}}{T_{L}-T_{S}} & T_{S} \leq T \leq T_{L} \\
1 & T>T_{L}
\end{array}\right.
$$

When the temperature ranges from $T_{S}$ to $T_{L}$, the equivalent specific heat $C_{p}{ }^{\prime}$ is extracted from Eq. 6:

$$
C_{p}^{\prime}=C_{p}+\frac{L}{T} \frac{T-T_{S}}{T_{L}-T_{S}}
$$

Similarly, when the temperature in the molten pool is above the boiling point $\left(T_{b}\right)$, the latent heat of evaporation $\left(L_{e}\right)$ can be considered in the FE model by using the equivalent specific heat $C_{p}{ }^{\prime \prime}$ :

$$
C_{p}^{\prime \prime}=C_{p}^{\prime}+\frac{L_{e} T-T_{b}}{T T_{\max }-T_{b}}
$$

Based on the Eqs. 7 and 8, the specific heat was artificially increased in the temperature range between the solidus and liquidus temperature and above the boiling point. During the thermal analysis, the modified specific heat was added to the "Material Mode" in the software [27].

\section{Mechanical Properties}

Tensile tests were performed to obtain the mechanical properties of A514 steel at room temperature. The results are shown in Fig. 2. Yield stress, Young's modulus, and Tangential modulus of the material at room temperature were achieved, as shown in Table 3. 


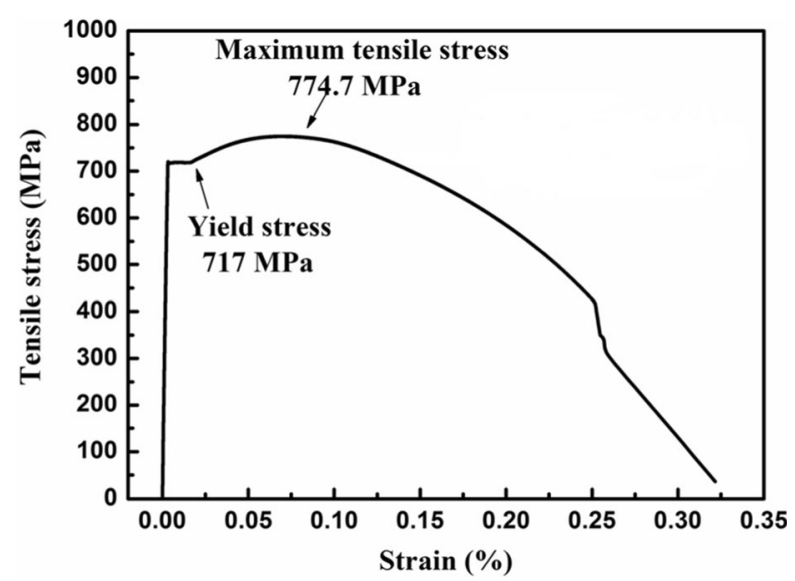

Fig. 2 Stress vs. strain curve for the ASTM A514 steel tensile coupon

A cut-off temperature, which is defined as $2 / 3$ of the melting temperature, is used to consider the effect of high-temperature mechanical properties on the numerical calculation [29]. Mechanical properties above the cut-off temperature have little influence on the numerically-predicted residual stress [30]. The melting temperature of A514 steel is $1500{ }^{\circ} \mathrm{C}$, and its vaporization temperature is $2800{ }^{\circ} \mathrm{C}$ [28]. A cut-off temperature of $1000^{\circ} \mathrm{C}$ was employed in this study. Based on the cut-off temperature method, Zhu and Chao [15] developed an engineering approximation in order to consider the yield stress $\sigma_{s}$ at high temperatures. Through this simplification equation, the numericallypredicted residual stress matched well with the experimental data.

$$
\sigma_{s}=\left\{\begin{array}{cc}
\sigma_{s 0}=717 \mathrm{MPa} & 0 \leq T \leq 100^{\circ} \mathrm{C} \\
5 \% \sigma_{s 0}+\frac{1000-T}{900} \times 95 \% \sigma_{s 0} & 100<T<1000^{\circ} \mathrm{C} \\
\sigma_{s}=5 \% \sigma_{s 0} & T \geq 1000^{\circ} \mathrm{C}
\end{array}\right.
$$

where $1000{ }^{\circ} \mathrm{C}$ is the cut-off temperature, and $717 \mathrm{MPa}$ is the material's yield stress obtained by the tensile test at room temperature.

Figure 3 shows the temperature-dependent mechanical properties used in the FE analysis. When the material's temperature is above the cut-off temperature, the steel loses its strength almost completely, and the elastic modulus (Young's modulus) is assumed negligible. A constant value of Poisson's ratio was used. The variation of Poisson's ratio with temperature has little effect on the numerical prediction of the residual stress [31]. The thermal expansion capability increases with an increase in the temperature.

Table 3 Mechanical properties of A514 steel plate at room temperature

\begin{tabular}{lllllll}
\hline $\begin{array}{l}\text { Temperature, } \\
{ }^{\circ} \mathrm{C}\end{array}$ & $\begin{array}{l}\text { Yield } \\
\text { stress, } \\
\mathrm{MPa}\end{array}$ & $\begin{array}{l}\text { Tensile } \\
\text { stress, } \\
\mathrm{MPa}\end{array}$ & $\begin{array}{l}\text { Young's } \\
\text { modulus, } \\
\mathrm{GPa}\end{array}$ & $\begin{array}{l}\text { Tangential } \\
\text { modulus, GPa }\end{array}$ & $\begin{array}{l}\text { Poisson's } \\
\text { ration }[28]\end{array}$ & $\begin{array}{l}\text { Thermal expansion } \\
\text { coefficient, } 10^{-5} /{ }^{\circ} \mathrm{C}[28]\end{array}$ \\
\hline 20 & 717 & 200 & 0.911 & 0.3 & 1.05 \\
\hline
\end{tabular}



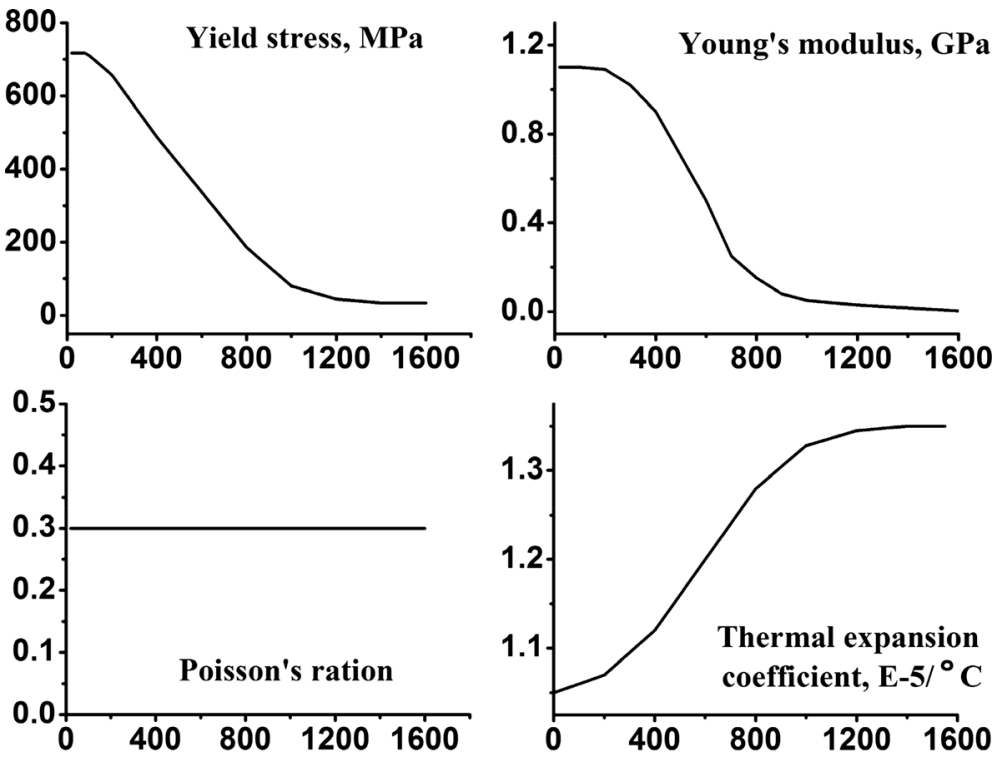

Fig. 3 Temperature-dependent mechanical properties used in the FE model

Stress-Strain Relation

When the thermal stress is below the yielding limit, the material is in the elastic state. The total strain increment consists of the elastic strain increment, $\varepsilon^{e}$, and the thermal expansion strain increment, $\varepsilon^{T}[32]$.

$$
\{d \varepsilon\}=\left\{d \varepsilon^{e}\right\}+\left\{d \varepsilon^{T}\right\}
$$

where $\varepsilon^{e}$ is modeled by using the isotropic Hook's law and is related to Young's modulus and Poisson's ratio. $\varepsilon^{T}$ is related to the thermal expansion coefficient.

When the thermal stress exceeds the yielding limit, the material becomes plastic. The plastic strain $\varepsilon^{P}$ is added to the total strain increment.

$$
\{d \varepsilon\}=\left\{d \varepsilon^{e}\right\}+\left\{d \varepsilon^{T}\right\}+\left\{d \varepsilon^{P}\right\}
$$

The von Mises yield criterion is used to predict the formation of the plastic strain. The software, ANSYS, provides an isotropic elastic-plastic constitutive relation to govern these three strains [27]. It is assumed that the strain rate has little effect on the plastic flow, and the material hardness is isotropic.

Cho and Kim [33] numerically studied the effect of solid-state phase transformation on the welding residual stress in the medium carbon steel and low carbon steel, respectively. The results showed that the solid-state phase transformation had an important influence on the predicted residual stress in the medium carbon steel, but had a slight effect in the case of low carbon steel. Deng [34] also found that the effect of solid-state phase transformation on the residual stress was insignificant during the arc welding of the low carbon steel. Sun et al. [35] simulated the laser welding of low carbon steel, and the effect of solid-state phase transformation was neglected. Thus, the effect of solid phase transformation was not considered in this study. 


\section{Mesh Independence}

Figure 4 presents the developed FE model used for the thermal and mechanical analysis. Only half of the welded structure was considered due to the symmetry of the structure. The mesh was non-linearly graded from fine to coarse size with increasing distance away from the weld centerline. The 8-node hexahedral brick element was applied to eliminate the negative effect of the degenerated triangle mesh during the mechanical analysis. The element type was SOLID70 for the thermal analysis, and SOLID180 for the mechanical analysis. The length of the smallest element in the weld center was $0.3 \mathrm{~mm}$ (in the longitudinal direction) $\times 0.3 \mathrm{~mm}$ (in the transverse direction) $\times 0.4 \mathrm{~mm}$ (in the thickness direction). The model contained 92,340 nodes and 88,406 elements.

The computing accuracy of the FE analysis relies intensely on the mesh size: the smaller the mesh size, the more accurate the solution, but the longer the computational time [36]. In order to maintain the calculation accuracy and, at the same time, reduce the computing time, the "grid independence" of the FE model, which was related to the continuity of the heat flux between adjacent elements, was investigated. A series of tests were conducted in the FE model by using finer meshes under the same material properties, element type, and boundary conditions. Only when the solution did not change with varying mesh size could the results be assumed to be reliable [11]. Fig. 5 shows the verification results of the grid independence. As shown, the numerical calculation of the FE model becomes independent from the mesh size when the number of nodes in the FE model is above 80,000. The number of nodes in the developed FE model should be larger than 80,000 in order to obtain reliable numerical results, but should be close to 80,000 in order to reduce the computing time.

\section{Results and Discussions}

In this work, an uncoupled thermo-mechanical analysis method was conducted to simulate the autogenous laser welding process [8, 10, 27]. The numerical simulation procedure consisted of two steps. First, the thermal analysis was conducted to calculate the temperature history in the welding process. Second, the obtained temperature
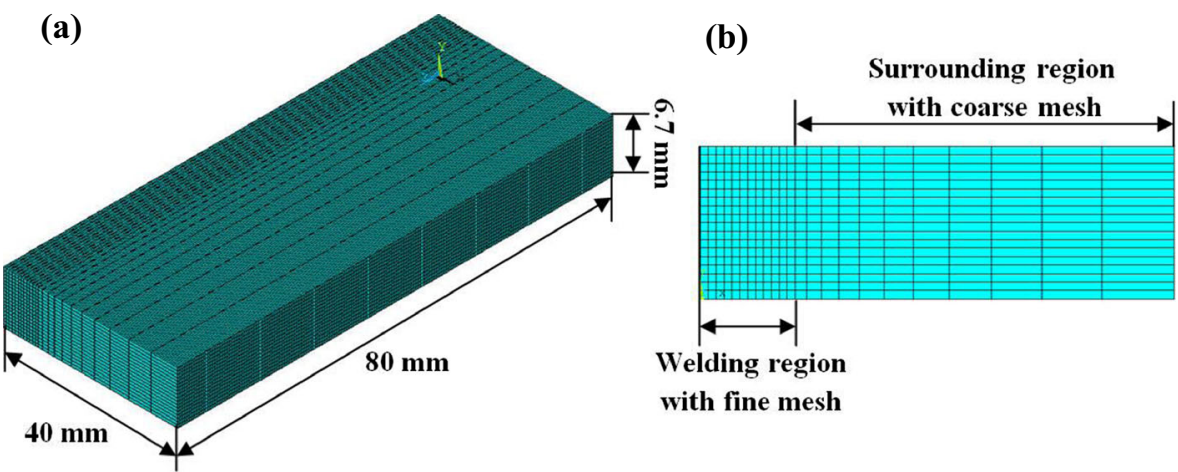

Fig. 4 Geometry and mesh distribution in the developed FE model: a 3D view of the model, b cross-section of the model 


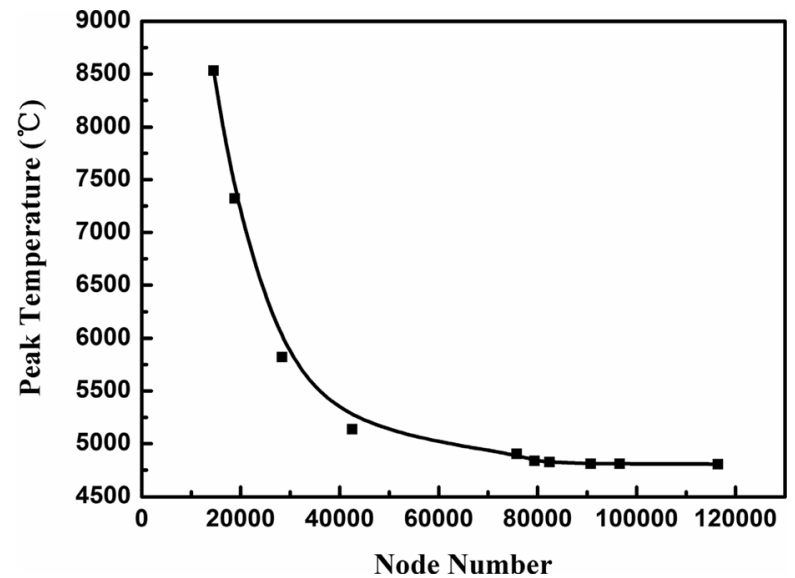

Fig. 5 Influence of the mesh size on the numerically-calculated peak temperature in the FE model

history was then applied into the same FE model to conduct the mechanical elasticplastic calculation analysis.

The computed 3D temperature profiles for two different welding speeds are shown in Fig. 6. Based on the melting point $\left(1500^{\circ} \mathrm{C}\right)$ and the vaporization point $\left(2800{ }^{\circ} \mathrm{C}\right)$ of A514 steel [28], the geometry of the keyhole and molten pool are determined, the thermal cycle of each node in this model is achieved, and the weld penetration and its width can be predicted. As shown, with a decrease in the welding speed, the heat input during welding increases, the size of the keyhole enlarges, and the molten pool broadens, resulting in a wider and deeper weld bead.

In order to verify the accuracy of the thermal analysis, the weld-bead shape predicted by the FE analysis was compared with the actual cross-section of the weld acquired under the optical microscope. As shown in Fig. 7a, the predicted contours agree well with the cross-section of the weld. The comparison between numerically-calculated thermal cycles and thermocouple data is given in Fig. 7b. Thermocouples, TC1 and $\mathrm{TC} 2$, were located at the top surface of the workpiece at 4.0 and $7.0 \mathrm{~mm}$ away from the

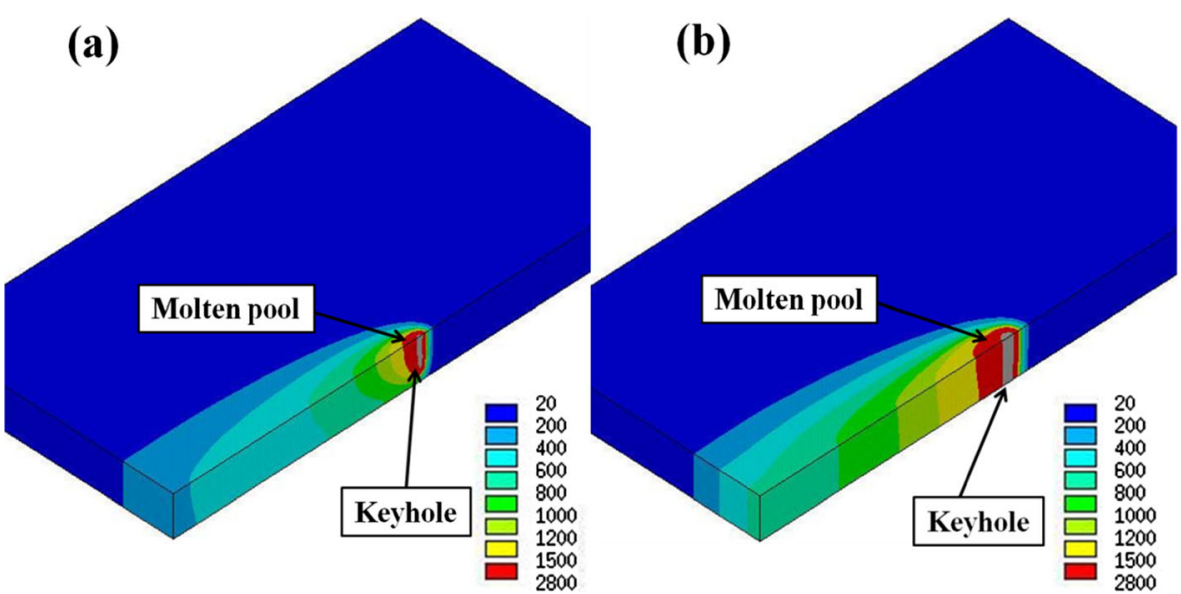

Fig. 6 The 3D temperature contours predicted by the FE analysis under a laser power of $4 \mathrm{~kW}$ and welding speeds of a $20 \mathrm{~mm} / \mathrm{s}$ and $\mathbf{b} 10 \mathrm{~mm} / \mathrm{s}$ 
(a)

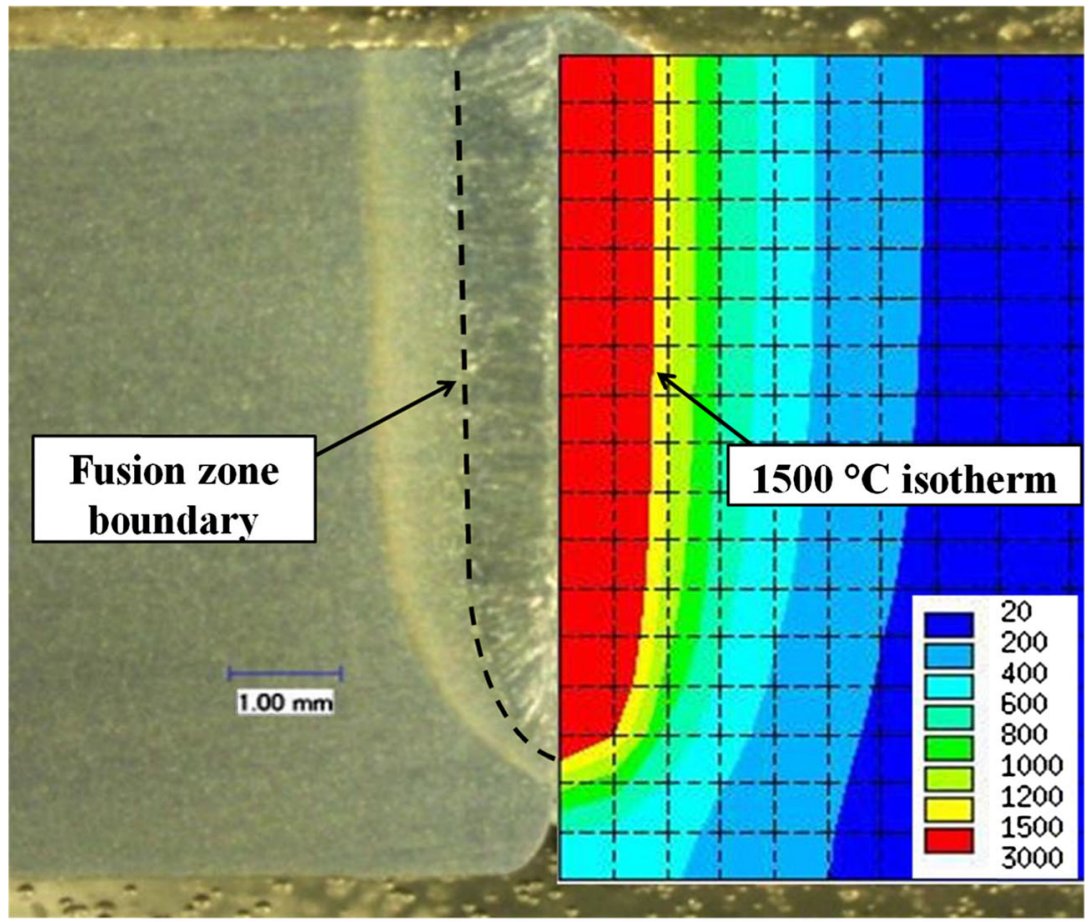

(b)

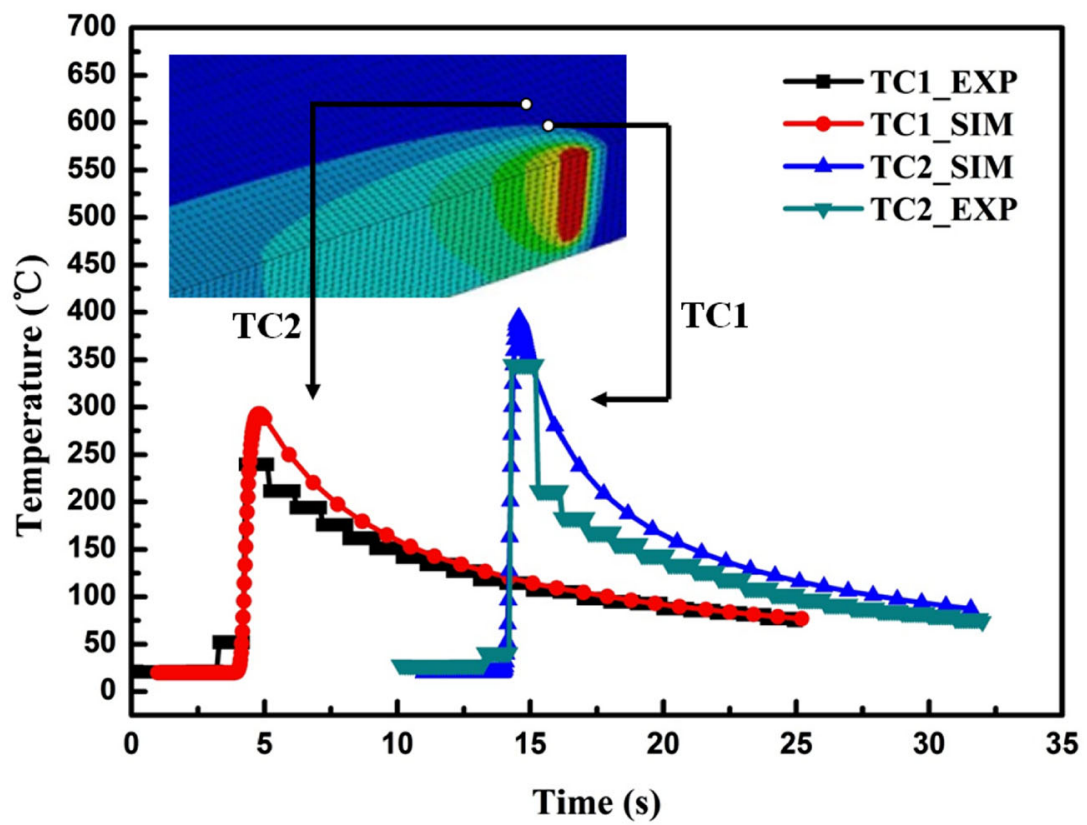

Fig. 7 Comparison between the numerical and experimental results for a laser power of $4 \mathrm{~kW}$ and a welding speed of $20 \mathrm{~mm} / \mathrm{s}$ : a cross-section comparison; and $\mathbf{b}$ temperature-history comparison 
weld centerline, respectively. As shown in Fig. 7b, the thermal cycles obtained by the FE analysis match well with the experimental results. Good agreement between the experimental and numerical results verifies the accuracy of the selected heat source model and thermal boundary conditions.

In this study, the total time steps used in the numerical calculation were equal to the value of the weld length over the length of an element along the direction of the heat flow. The needed distance for the heat source traveling between the adjacent time steps was equal to the length of an element. Figure 8 a shows the temperature distribution along the weld centerline versus the time step. As shown, the temperature at the starting
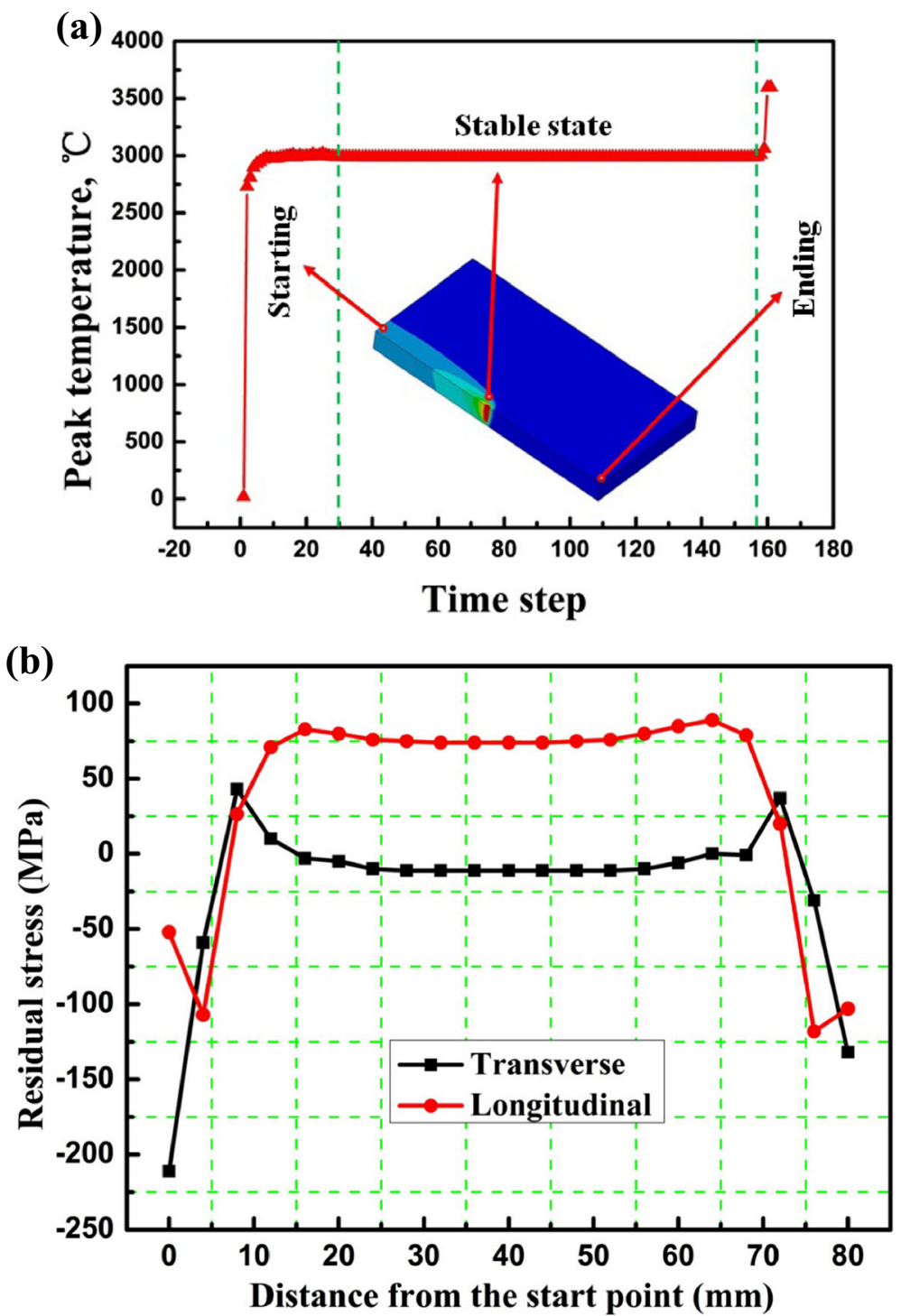

Fig. 8 Evolution of the temperature field and residual stress along the weld centerline for a laser power of $4 \mathrm{~kW}$ and a welding speed of $20 \mathrm{~mm} / \mathrm{s}$, a peak temperature vs. time step, b residual stresses vs. weld length 
stage is rising from 20 to $3000{ }^{\circ} \mathrm{C}$ with the time steps ranging from 2 to 30 . The temperature increases sharply, and the temperature gradient between adjacent time steps is large. With the moving of the heat source along the welding direction, the temperature difference gradually decreases to zero, and the welding process reaches a steady state. The heat flux is uniformly distributed in the FE model at the steady-state stage, indicating that there is no variation in the heat flux between adjacent elements. Correspondingly, the distributions of the transverse and longitudinal residual stresses are uniform along the weld centerline at the steady-state stage (see Fig. 8b). When the heat source approaches the final part of this model, the temperature rises again due to the edge effect. At the edge of this FE model, the heat lost induced by the convection and radiation decreases with an increase in the surface area in contact with the air. The heat transfer coefficient of the material is larger than that of the air, leading to the rise of temperature profiles. At the starting and ending stages, there exist large temperature gradients between adjacent elements, leading to the large variation in the values of residual stresses. The uniform distributions of residual stresses are achieved when the temperature gradient between adjacent elements is zero.

Another case with a laser power of $4 \mathrm{~kW}$ and a welding speed of $10 \mathrm{~mm} / \mathrm{s}$ was calculated to investigate the effect of the welding speed on the residual stress. The accuracy of the thermal analysis was verified in Fig. 9. The comparison between the numerically-predicted and experimentally-obtained thermal cycles was not conducted because the thermal boundary conditions were unchanged with respect to the case shown in Fig. 7. The effect of the welding speed on the distribution of the residual stress is shown in Fig. 10. As shown, the numerically-obtained transverse and

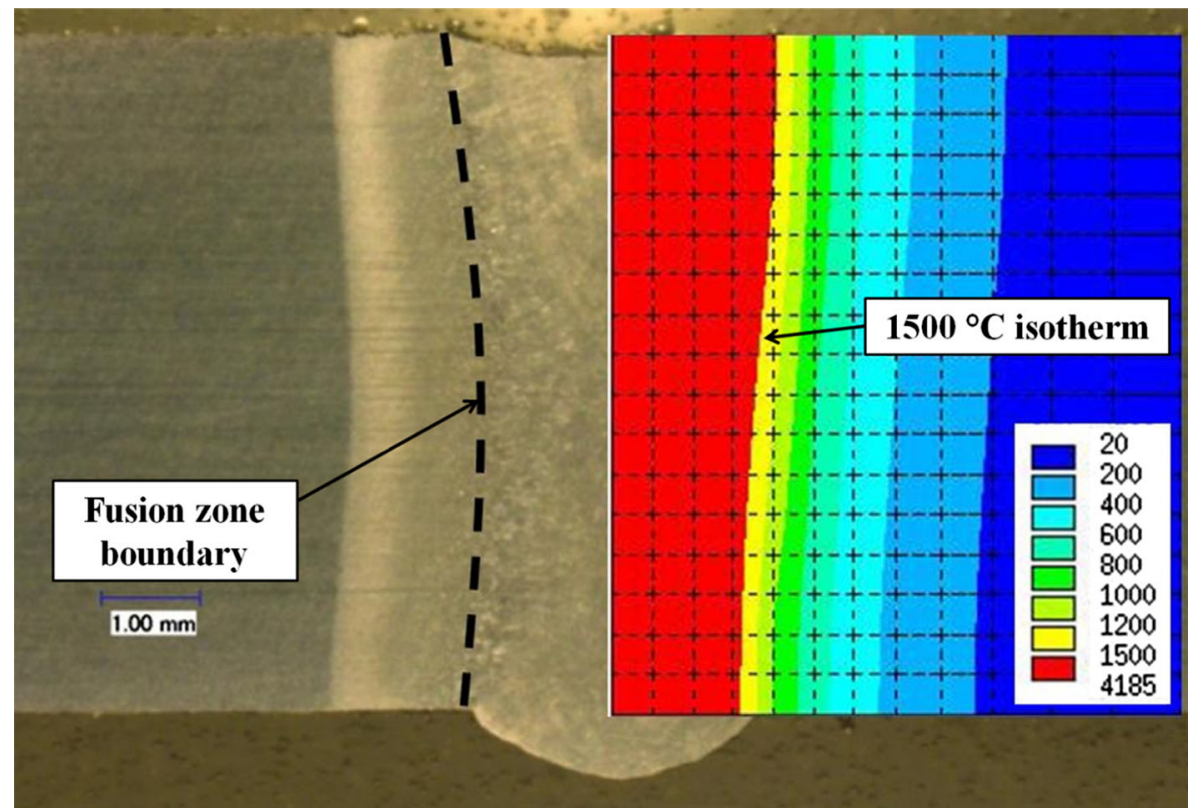

Fig. 9 Comparison between the numerically-predicted and experimentally-obtained cross-section of the weld bead 

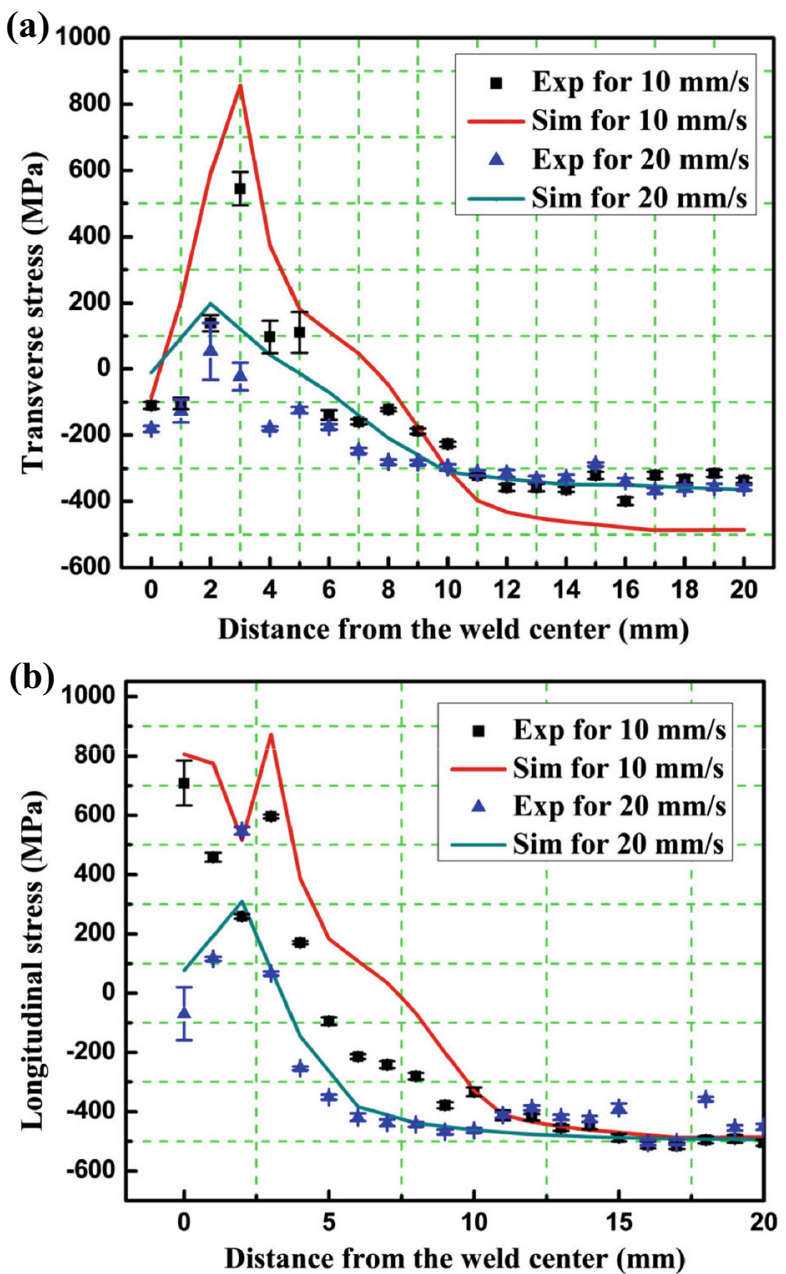

Fig. 10 Effect of the welding speed on the residual stresses: a transverse residual stress and b longitudinal residual stress

longitudinal residual stresses agree well with the experimental data measured by the $\mathrm{XRD}$ technique for both cases. With an increase in the welding speed, both transverse
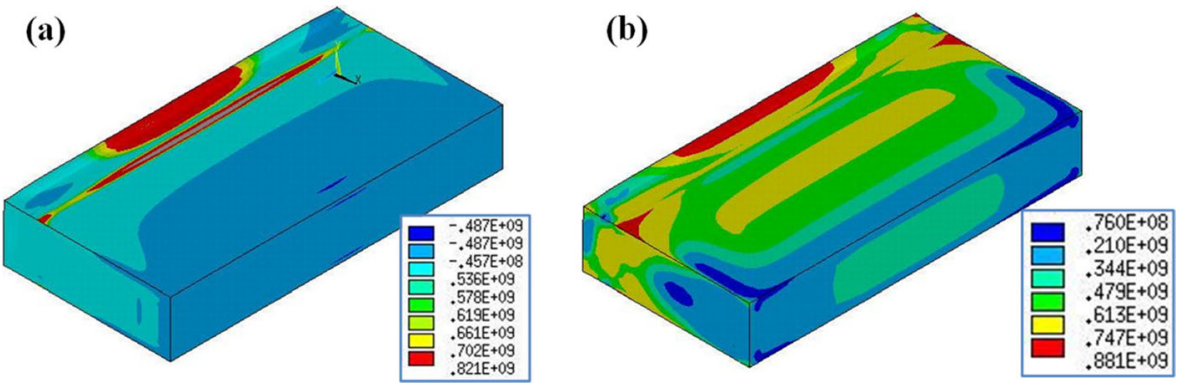

Fig. 11 Numerically-predicted 3D residual-stress distributions for a laser power of $4 \mathrm{~kW}$ and a welding speed of $10 \mathrm{~mm} / \mathrm{s}$ : a longitudinal stress and $\mathbf{b}$ von Mises equivalent stress (SEQV) 
and longitudinal residual stresses experience a general decrease due to a decrease in the heat input during welding.

The FE analysis results give detailed information about 3D residual-stress field inside the welded structure. Figure 11 shows the predicted distribution of the longitudinal stress and the von Mises equivalent stress (SEQV). As shown, SEQV in the weld zone has a magnitude larger than $747 \mathrm{MPa}$. The yielding stress of the A514 steel is $717 \mathrm{MPa}$. Thus, there are the plastic strains and residual stress retained in the weld zone and its vicinity. As shown in Fig. 11 a and b, the high tensile residual stress is concentrated in the middle section of the developed model. This may be caused by the small size of the FE model.

The FE mechanical analysis gives detailed spatial and temporal information about the evolution and distribution of the residual stress. Figure 12 shows the variation of the residual stress as a function of the welding time along the line AB. As shown in Fig. 12d, the line $\mathrm{AB}$ is located in the middle of the weld. The time when the laser head reaches the line $\mathrm{AB}$ is $4.0 \mathrm{~s}$. When the laser beam (heat source) is away from the line $\mathrm{AB}(t \leq 3.5 \mathrm{~s})$, a high compressive stress (initial stress) is presented in the weld zone and base material. When the laser beam approaches the line $\mathrm{AB}$, the temperature of the material near the line $\mathrm{AB}$ increases, resulting in the expansion of the heated material. The expansion is inhibited by the surrounding material, resulting in an increase in the longitudinal compressive stress $(3.5 \mathrm{~s}<t<4.0 \mathrm{~s})$. With respect to the longitudinal stress, the transverse stress has little

(a)

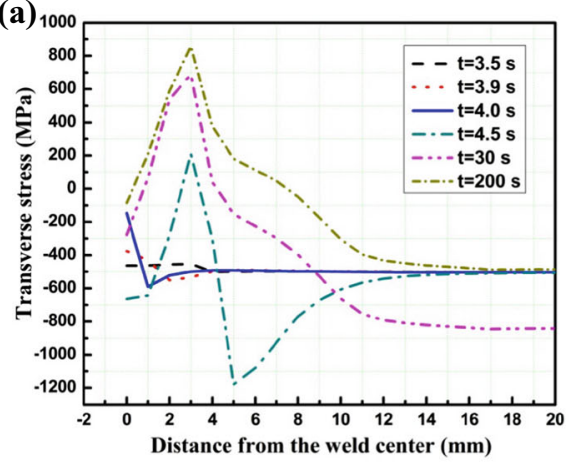

(c)

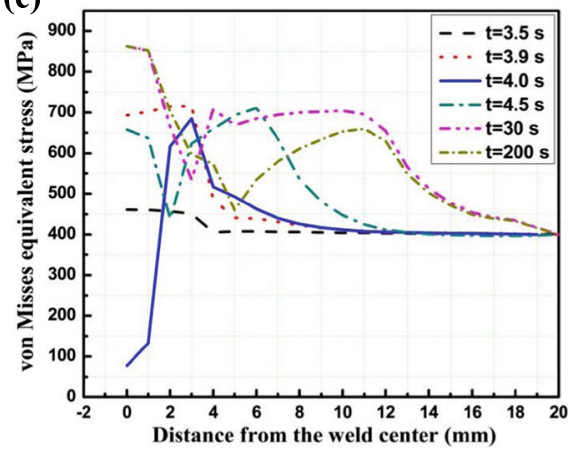

(b)

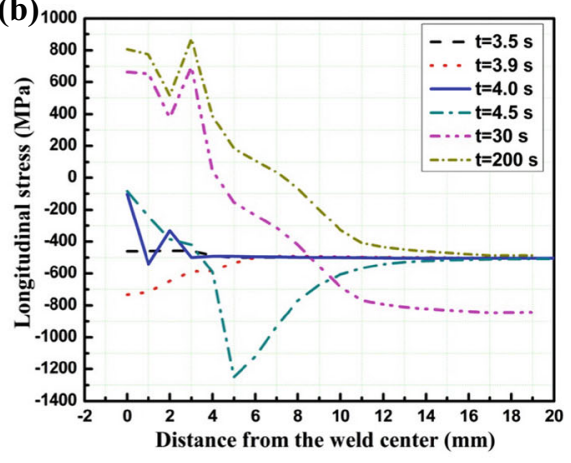

(d)

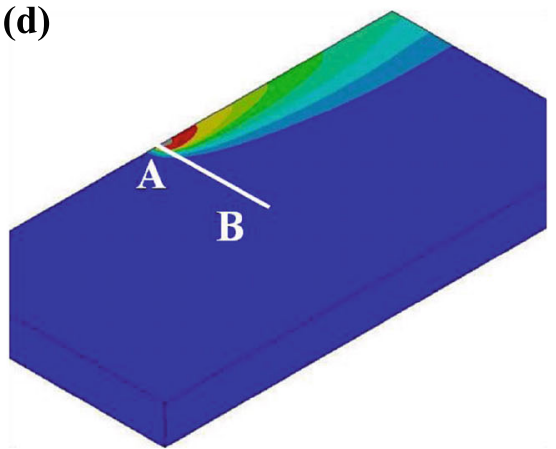

Fig. 12 Residual stresses vs. welding time for a laser power of $4 \mathrm{~kW}$ and a welding speed of $10 \mathrm{~mm} / \mathrm{s}, \mathbf{a}$ transverse stress, $\mathbf{b}$ longitudinal stress, $\mathbf{c}$ von Mises equivalent stress, and $\mathbf{d}$ temperature contours at a time of $3.9 \mathrm{~s}$ 
change in the weld zone with the approaching of the heat source, indicating that the expansion of the heated material in the transverse direction is not apparent in comparison to the expansion in the longitudinal direction. When the laser beam passes the line $\mathrm{AB}(t>$ $4.0 \mathrm{~s}$ ), the expanded material starts to contract due to the cooling of the material. The contracted region is retained by the surrounding area, leading to the decrease in the transverse and longitudinal compressive stresses. The compressive stress is gradually transferred to the tensile stress in the weld zone when the weld cools down. Von Mises equivalent stress has a sharp decrease at the time of $4.0 \mathrm{~s}$ when the material near the line $\mathrm{AB}$ is in the molten state and has the maximum temperature (see Fig. 12c). The plastic strain is formed because the thermal stress could easily exceed the thermally-reduced von Mises equivalent stress at the time of $4.0 \mathrm{~s}$. The plastic deformation could not be relieved after the weld cools down, resulting in the formation of residual stresses.

Figure 13 shows the residual-stress distribution along the cross-section of the weld at different thicknesses. The values of the thicknesses, $y$, at the top and bottom surfaces
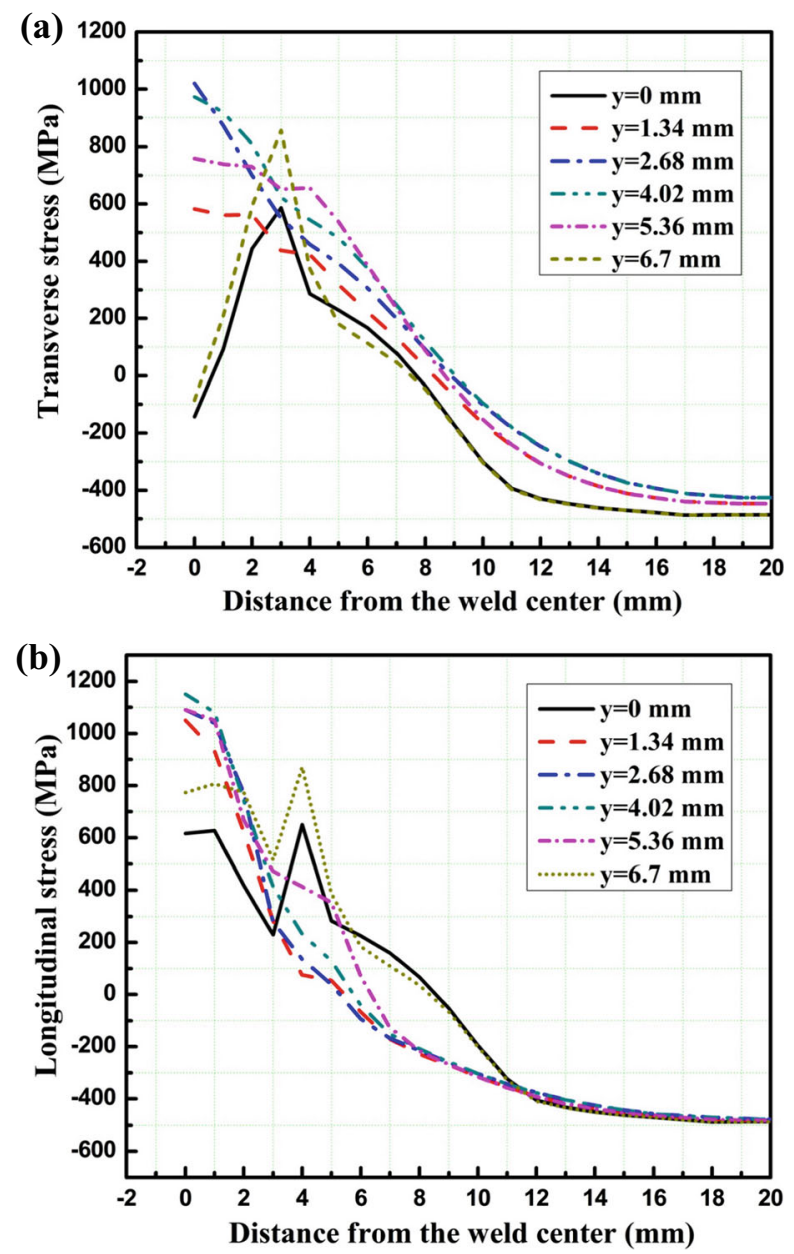

Fig. 13 Residual-stress distribution along the cross-section of the weld at different thicknesses: a transverse residual stress and $\mathbf{b}$ longitudinal residual stress 
are 6.7 and $0 \mathrm{~mm}$, respectively. It is noted that in the weld zone, the distributions of residual stresses at the top and bottom surface are similar but are different from the stress distribution inside the weld bead. For the transverse residual stress (see Fig. 13a), a compressive stress is presented at the top and bottom surfaces in the weld center. However, a high tensile transverse stress exists inside the weld bead. In the case of longitudinal residual stress (see Fig. 13b), the tensile longitudinal stress is located in the weld zone for all positions along the weld thickness direction. However, the longitudinal stress presented inside the weld bead has a higher value than the stress located at the top and bottom surfaces.

Before welding, the residual stress at the top surface of A514 steel was measured by the XRD technique. The results are shown in Fig. 14. When measuring the initial stresses, the square map was chosen to settle the measurement points [18]. The points were measured along the edges of the square and then interpolated. As shown, a transverse compressive stress of around $350 \mathrm{MPa}$ and a longitudinal compressive stress of around $500 \mathrm{MPa}$ are presented at the top surface of the A514 steel plate. These high compressive residual stresses were introduced by the preceding manufacturing processes and presented in the steel plate as initial stress. The effect of initial stress on the numerical simulation was investigated. "INISTATE" command in the ANSYS software was used to apply initial stress on the element-based FE model. This command was
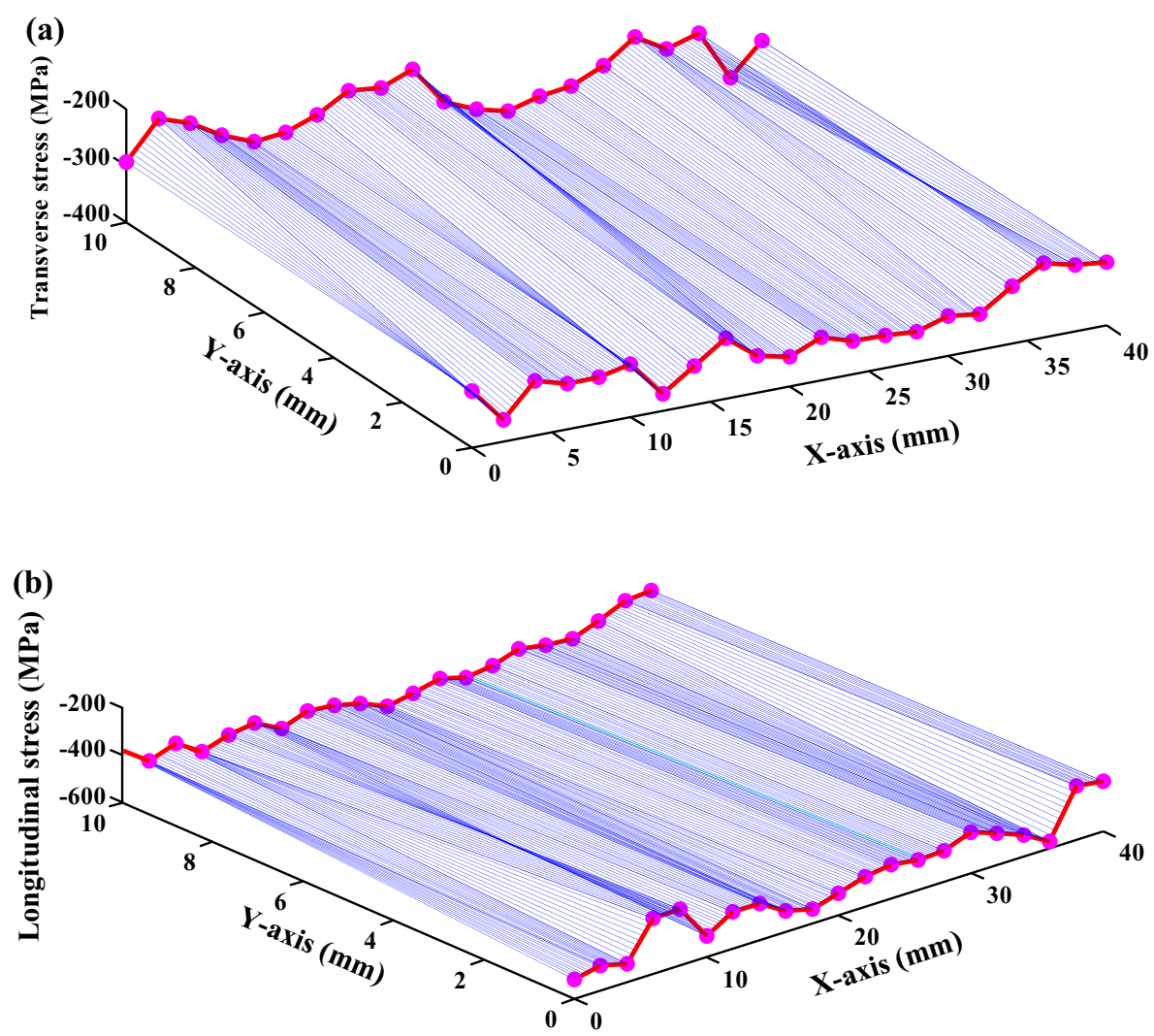

Fig. 14 Initial stresses presented in the base material: a transverse stress and $\mathbf{b}$ longitudinal stress 
coded by using the ANSYS Program Design Language. It was assumed that all elements in the FE model had the same distribution of initial stress. Transverse and longitudinal initial stresses defined as -350 and $-500 \mathrm{MPa}$, respectively, were added to all elements in the FE model.

Two cases with and without considering initial stress were considered. The numerically-calculated results were compared with the experimental data measured by the XRD machine, as shown in Fig. 15. As shown, initial stress has a significant influence on the results obtained by the numerical simulation. If initial stress is not considered, a large difference between the numerical and experimental results occurs for both transverse and longitudinal residual stresses, especially in the region away from the weld centerline. When initial stress is considered, a good agreement between numerically-predicted and experimentally-measured residual stresses is achieved.
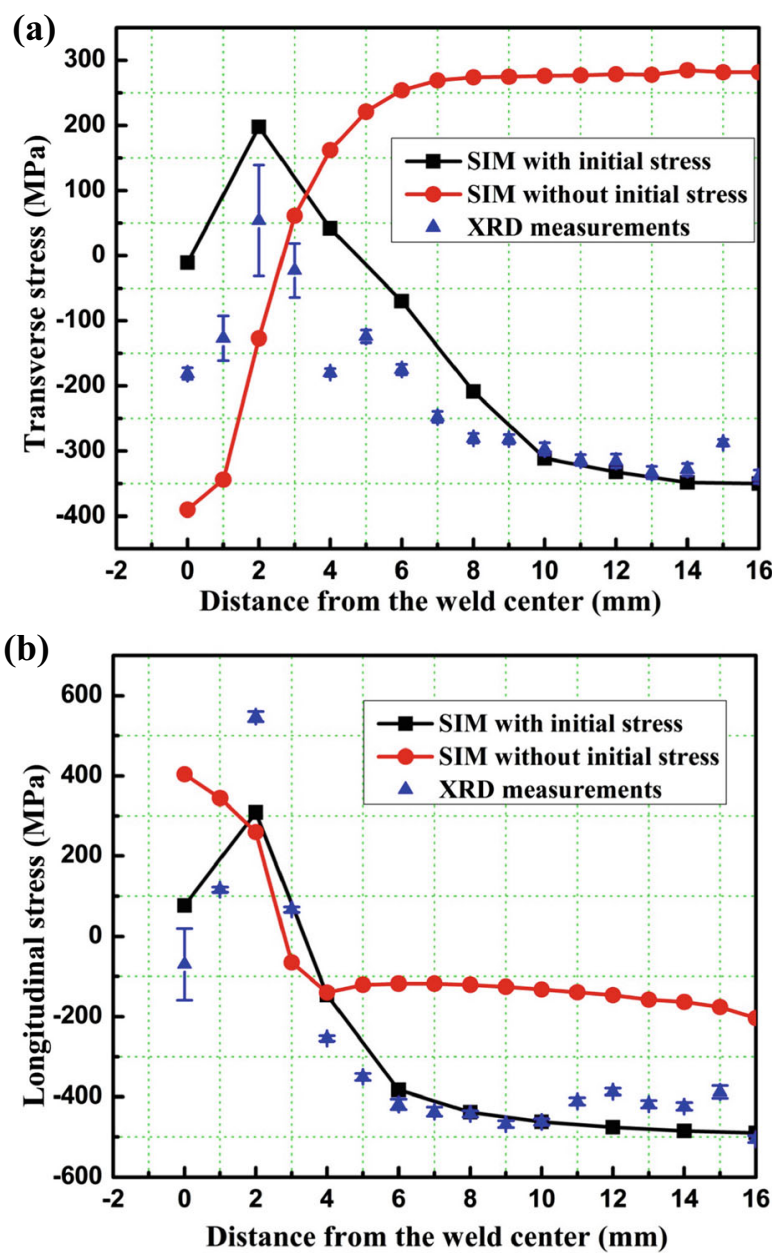

Fig. 15 Effect of initial stress on the numerically-predicted residual stresses: a transverse residual stress and b longitudinal residual stress 


\section{Conclusions}

A 3D FE model was developed to simulate the thermal field and thermally-induced residual stress during autogenous laser welding of high-strength steel. Important conclusions are presented as the following:

1) Tensile testing was conducted on the base material in order to achieve the mechanical properties at room temperature. The mechanical properties at high temperatures were then simplified through a cut-off temperature method.

2) The grid independence of the FE model was verified to guarantee the continuity of the heat flux between adjacent elements. Uniform distribution of temperature determined the consistency of residual stress predicted in the FE model.

3) The thermal and mechanical results obtained by the FE analysis agreed well with the experimental results measured by an XRD technique. The verified numerical results provided detailed information about the evolution and distribution of residual stress during welding.

4) Two cases with different welding speed were modeled in this work. It was found that with an increase in the welding speed, both transverse and longitudinal residual stresses decreased due to a decrease in the heat input during welding.

5) A514 steel plates used for welding had a high compressive initial stress. A subroutine was developed to consider the effect of initial stress on the FE analysis. It was found that a big discrepancy between experimental and numerical results occurred when initial stress was not considered in the FE model.

Acknowledgments The financial support by NSF's Grant No. IIP-1034652 is acknowledged. The authors also would like to thank the engineer Andrew Socha for the help in the execution of experiments.

\section{References}

1. Ma, J., Kong, F., Liu, W., Carlson, B., Kovacevic, R.: Study on the strength and failure modes of laser welded galvanized DP980 steel lap joints. J. Mater. Process. Technol. 214(8), 1696-1709 (2014)

2. Liu, W., Liu, S., Ma, J., Kovacevic, R.: Real-time monitoring of the laser hot-wire welding process. Opt. Laser Technol. 57, 66-76 (2014)

3. Liu, W., Ma, J., Yang, G., Kovacevic, R.: Hybrid laser-arc welding of advanced high-strength steel. J. Mater. Process. Technol. 214(12), 2823-2833 (2014)

4. Colegrove, P., Ikeagu, C., Thistlethwaite, A., Williams, S., Nagy, T., Suder, W., Steuwer, A., Pirling, T.: Welding process impact on residual stresses and distortion. Sci. Technol. Weld. Join. 14, 717-725 (2009)

5. Hatamleh, O., Rivero, I., Lyons, J.: Evaluation of surface residual stresses in friction stir welds due to laser and shot peening. J. Mater. Eng. Perform. 16, 549-553 (2007)

6. Qian, Z., Chumbley, S., Karakulak, T., Johnson, E.: The residual stress relaxation behavior of weldments during cyclic loading. Metall. Mater. Trans. A 44(7), 3147-3156 (2013)

7. Gong X, Anderson T, Chou K.: Review on powder-based electron beam additive manufacturing technology. In ASME/ISCIE 2012 International Symposium on Flexible Automation. American Society of Mechanical Engineers, (pp. 507-515) (2012)

8. Deng, D., Luo, Y., Serizawa, H., Shibahara, M., Murakawa, H.: Numerical simulation of residual stresses and deformation considering phase transformation effect. Trans. JWRI 32, 325-333 (2003)

9. Zain-ul-Abdein, M., Nelias, D., Jullien, J., Deloison, D.: Prediction of laser beam welding-induced distortions and residual stresses by numerical simulation for aeronautic application. J. Mater. Process. Technol. 209, 2907-2917 (2009) 
10. Kong, F., Ma, J., Kovacevic, R.: Numerical and experimental study of thermally induced residual stress in the hybrid laser-GMA welding process. J. Mater. Process. Technol. 211(6), 1102-1111 (2011)

11. Gross, M.: Comprehensive numerical simulation of laser materials processing. In: Dowden, J. (ed.) The theory of laser materials processing: heat and mass transfer in modern technology, pp. 339-380. Springer, New York (2009)

12. Radaj, D.: Welding residual stresses and distortion: calculation and measurement, 2nd edn, pp. 118-200. Verlag für Schweissen und Verwandte Verfahren, DVS-Verlag (2003)

13. Heinze, C., Schwenk, C., Rethmeier, M.: Influences of mesh density and transformation behavior on the result quality of numerical calculation of welding induced distortion. Simul. Model. Pract. Theory 19, $1847-1859$ (2011)

14. Blodgett, O.: Types and causes of distortion in welded steel and corrective measures. Weld. J. 39, 692-697 (1960)

15. Zhu, X., Chao, Y.: Effects of temperature-dependent material properties on welding simulation. Comput. Struct. 80, 967-976 (2002)

16. Tsai, C., Kim, D.: Understanding residual stresses and distortion in welds: an overview. Processes and mechanisms of welding residual stresses and distortion. In: Feng, Z. (ed.) Processes and mechanisms of welding residual stresses and distortion, pp. 3-6. CRC Press, Florida (2005)

17. Qian, Z., Chumbley, S., Johnson, E.: The effect of specimen dimension on residual stress relaxation of carburized and quenched steels. Mater. Sci. Eng. A 529, 246-252 (2011)

18. Liu W, Kong F, Kovacevic R.: Residual Stress Analysis and Weld Bead Shape Study in Laser Welding of High Strength Steel. In ASME 2013 International Manufacturing Science and Engineering Conference collocated with the 41 st North American Manufacturing Research Conference. American Society of Mechanical Engineers, pp. V001T01A053-V001T01A053, (2013)

19. Steen, W., Mazumder, J.: Laser material processing, 4th edn, pp. 255-257. Springer, New York (2010)

20. Farahmand, P., Kovacevic, R.: An experimental-numerical investigation of heat distribution and stress field in single-and multi-track laser cladding by a high-power direct diode laser. Opt. Laser Technol. 63, 154-168 (2014)

21. Bag, S., Trivedi, S., De, A.: Development of a finite element based heat transfer model for conduction mode laser spot welding process using an adaptive volumetric heat source. Int. J. Therm. Sci. 48, 19231931 (2009)

22. Frewin, M.R., Scott, D.A.: Finite element modal of pulsed laser welding. Weld. Res. Suppl. 78, 15-22 (1999)

23. Brown, S., Song, H.: Finite element simulation of welding of large structures. J. Manuf. Sci. Eng. 114, 441-451 (1992)

24. Tsirkas, S., Papanikos, P., Kermanidis, T.: Numerical simulation of the laser welding process in butt-joint specimens. J. Mater. Process. Technol. 134, 59-69 (2003)

25. Cho, J., Na, S.: Three-dimensional analysis of molten pool in GMA-laser hybrid welding. Weld. J. 88, 3543 (2009)

26. Piekarska, W., Kubiak, M.: Three-dimensional model for numerical analysis of thermal phenomena in laser-arc hybrid welding process. Int. J. Heat Mass Transf. 54, 4966-4974 (2011)

27. ANSYS Inc.: ANSYS 11.0 manual (2007)

28. Kong, F., Kovacevic, R.: Development of a comprehensive process model for hybrid laser-Arc welding. In: Kovacevic, R. (ed.) Welding processes, pp. 164-174. Intech, New York (2012)

29. Tekrewal, P.: Transient and residual thermal strain-stress analysis of GMAW. Trans. ASME J. Eng. Mater. Technol 113, 336-343 (1991)

30. Börjesson, L., Lindgren, L.: Simulation of multipass welding with simultaneous computation of material properties. J. Eng. Mater. Technol. 123, 106-111 (2001)

31. Tekriwal, P., Mazumder, J.: Transient and residual thermal strain-stress analysis of GMAW. J. Eng. Mater. Technol. 113(3), 336-343 (1991)

32. Li, C., Wang, Y., Zhan, H., Han, T., Han, B., Zhao, W.: Three-dimensional finite element analysis of temperatures and stresses in wide-band laser surface melting processing. Mater. Des. 31(7), 3366-3373 (2010)

33. Cho, S.H., Kim, J.W.: Analysis of residual stress in carbon steel weldment incorporating phase transformations. Sci. Technol. Weld. Join. 7(4), 212-216 (2002)

34. Deng, D.: FEM prediction of welding residual stress and distortion in carbon steel considering phase transformation effects. Mater. Des. 30(2), 359-366 (2009)

35. Sun, J., Liu, X., Tong, Y., Deng, D.: A comparative study on welding temperature fields, residual stress distributions and deformations induced by laser beam welding and $\mathrm{CO}_{2}$ gas arc welding. Mater. Des. 63, 519-530 (2014)

36. Komanduri, R., Hou, Z.: Thermal analysis of the arc welding process: Part I. General solutions. Metall. Mater. Trans. B 31, 1353-1370 (2000) 